Case Report

\title{
HIV Infection and Osteoarticular Tuberculosis: Strange Bedfellows
}

\author{
B. Hodkinson, ${ }^{1}$ N. Osman, ${ }^{2}$ and S. Botha-Scheepers ${ }^{1}$ \\ ${ }^{1}$ Department of Medicine, Division of Rheumatology, University of Cape Town and Groote Schuur Hospital, \\ Cape Town 7945, South Africa \\ ${ }^{2}$ Division of Anatomical Pathology, National Health Laboratory Service, University of Cape Town and Groote Schuur Hospital, \\ Cape Town 7945, South Africa
}

Correspondence should be addressed to B. Hodkinson; drbridget@gmail.com

Received 13 January 2016; Accepted 9 May 2016

Academic Editor: Suleyman Serdar Koca

Copyright ( $\odot 2016$ B. Hodkinson et al. This is an open access article distributed under the Creative Commons Attribution License, which permits unrestricted use, distribution, and reproduction in any medium, provided the original work is properly cited.

We report the case of a 47-year-old female patient with rheumatoid arthritis and HIV infection presenting with a 3-week history of a painful swollen knee, increased serum inflammatory markers, and a low CD4 lymphocyte count. The diagnosis of TB arthritis was made by synovial fluid culture, GeneXpert/PCR, and confirmed by histopathology of a synovial biopsy. A mini literature review suggests that although HIV infection is associated with extrapulmonary TB, osteoarticular TB is a relatively unusual presentation in an HIV positive patient. The diagnostic utility of the GeneXpert test is explored. We also describe the patient's good response to an intra-articular corticosteroid injection in combination with standard anti-TB therapy.

\section{Introduction}

Patients infected with human immunodeficiency virus (HIV) are at increased risk of tuberculosis (TB) coinfection. We describe an unusual presentation of HIV and TB coinfection in a patient with rheumatoid arthritis (RA). We present a mini literature review and discussion regarding 3 aspects of this case:

(i) the association between HIV and osteoarticular TB;

(ii) diagnostic tests;

(iii) adjuvant management.

\section{Case Presentation}

A 47-year-old female with seropositive RA was diagnosed 6 years previously with a 3-week history of a painful right knee. She reported no fever, night sweats, cough, or loss of weight and had received no recent intra-articular steroid injections. Two years earlier she was diagnosed with HIV infection and was initiated on combination antiretroviral (ARV) therapy (tenofovir/efavirenz/emtricitabine). Her RA therapy consisted of methotrexate (MTX) $15 \mathrm{mg}$ weekly and prednisone $7.5 \mathrm{mg}$ daily and the RA had been in remission for 24 months prior to this presentation. She had no history of previous TB.

Examination revealed a thin middle-aged female with a swollen tender right knee with a reduced range of motion. She was afebrile with clinically inactive RA, and there was no tenderness or swelling of her other joints. Blood investigations showed a normochromic anaemia (hemoglobin = $10.3 \mathrm{~g} / \mathrm{dL}$ ), leukocytosis (WCC $=19.3 \times 10^{9} / \mathrm{L}$ ), and thrombocytosis (platelet $=486 \times 10^{9} / \mathrm{L}$ ). Her C-reactive protein was elevated $(340 \mathrm{mg} / \mathrm{L})$ and CD4 cell count was low $\left(199 / \mathrm{mm}^{3}\right)$. Chest and knee radiographs were normal. Pus was aspirated from the right knee and submitted for microbiology with Gram and Ziehl-Neelsen stain negative. GeneXpert on the fluid was positive. Culture was positive at 21 days for Mycobacterium tuberculosis. A synovial biopsy submitted for histology revealed necrotising granulomatous inflammation and the Ziehl-Neelsen stain was positive for acid-fast bacilli (Figures 1-3) confirming the diagnosis of osteoarticular TB/tubercular arthritis. MTX was discontinued, and combination antituberculous therapy was started. Due to the 


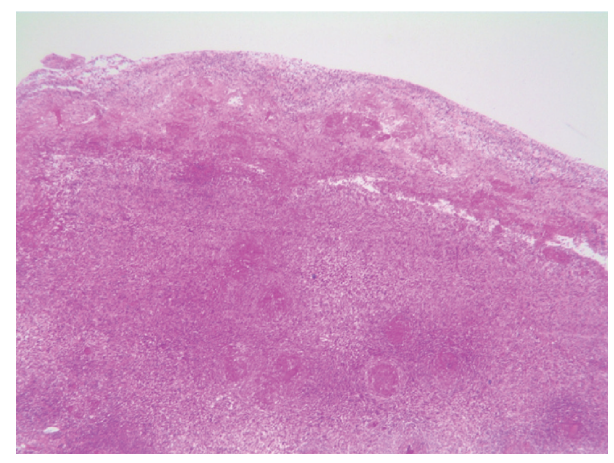

FIgURE 1: Haematoxylin and Eosin (H\&E) stain of the synovial biopsy showing foci of granulomatous inflammation (20x magnification).

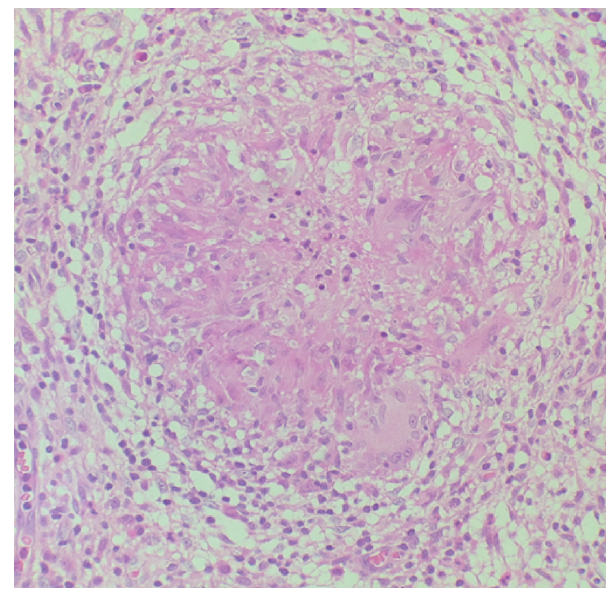

FIGURE 2: $\mathrm{H}+\mathrm{E}$ stain of synovial biopsy showing granulomatous inflammation (400x magnification).

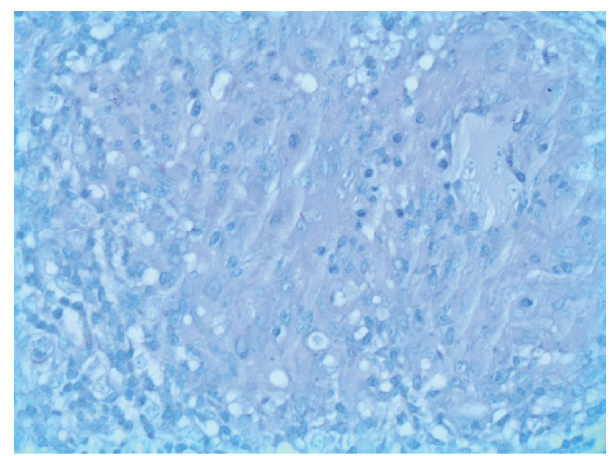

FIgURE 3: Ziehl-Neelsen stain of synovial biopsy showing acid-fast bacillus (arrow) (400x magnification).

ongoing symptoms of the arthritis, a single intra-articular corticosteroid injection (methylprednisolone acetate $80 \mathrm{mg}$ ) was administered. Clinical improvement and a good range of motion of the right knee were noted within 2 weeks. At her follow-up visit at 3 months she was symptom-free and had recovered the full range of motion of the joint. Her blood counts normalised, her CRP was 3, and the CD4 cell count improved to $410 / \mathrm{mm}^{3}$.

\section{Discussion}

The single most important risk factor for contracting TB is HIV infection, particularly in Sub-Saharan Africa where HIV-related TB comprises $79 \%$ of TB cases [1]. In particular, extrapulmonary forms of TB (ExP-TB) are encountered in HIV positive patients with low CD4 lymphocyte counts. Skeletal TB is an uncommon form of ExP-TB and affects either the spine (comprising $5 \%$ of ExP-TB) or peripheral joints as "osteoarticular TB (OA-TB)" which constitutes a further $5 \%$ of ExP-TB. Usually presenting as a chronic monoarthritis, most often affecting the hip, knee, or wrist joint, OA-TB typically has an insidious onset without constitutional symptoms or features of pulmonary TB [2].

Many reports claim a strong association between OA$\mathrm{TB}$ and HIV infection, including a review from Zambia that describes $60 \%$ of OA-TB cases as HIV-associated [3]. However, studies of OA-TB, including studies from areas of high HIV prevalence, report very few HIV positive cases (Table 1), suggesting that HIV infection may not be a risk factor for OATB. It has been shown in Soweto, South Africa, that although $\mathrm{HIV}$ is associated with ExP-TB, the relative frequency of OATB amongst HIV positive patients was significantly lower than in HIV negative patients [4]. A South African study of TB-associated skeletal changes revealed an increase in the number of cases with skeletal TB, from 28\% in the pre-1985 era to $41 \%$ after 1985 [5]. In the case of TB spine, there may be more convincing evidence of an association with HIV, with $17-33 \%$ of cases testing HIV positive in areas with a high prevalence of HIV (such as South Africa, Nigeria, Morocco, and Spain) and a much lower incidence (0-8\%) elsewhere [6]. A recent report from SA described 20 cases of TB spine with half of these patients coinfected with HIV [7]. HIV positive patients have been shown to have less vertebral body destruction and more abscess formation compared to HIV negative patients. Microscopic features between the two groups are similar but an inverted CD4 : CD8 lymphocyte ratio is seen within the granulomas of patients coinfected with $\operatorname{HIV}[8,9]$.

The synovial fluid of our patient was GeneXpert positive. GeneXpert MTB/RIF (Cepheid, Sunnyvale, CA, USA) is a polymerase chain reaction (PCR) assay allowing rapid diagnosis of TB and detection of resistance to rifampicin. Sputum GeneXpert detects with a high specificity the majority of pulmonary TB cases and is a useful screening test for ExPTB, in particular CSF and tissue specimens [10]. For the diagnosis of TB spine, PCR tests on pus or vertebral bone samples have a very high sensitivity and specificity (96\% and 96-100\%, resp.) [11, 12]. In the case of synovial fluid, PCR tests have shown moderate sensitivity (63\%) but excellent specificity (92-100\%) [13]. Thus PCR tests are a useful and very convenient test for OA-TB, but synovial biopsy should be performed in patients with a negative test. A recent study from Mexico demonstrated the excellent clinical utility of serum PCR in the diagnosis of spine and OA-TB, with sensitivity and specificity of $91 \%$ and $97 \%$, respectively [14].

The patient described in this case study was on MTX, low dose oral corticosteroids, and ARV therapy. The safety of MTX in patients who are HIV positive is uncertain. In patients with low CD4 counts, MTX may predispose patients 
TABLE 1: Case series of osteoarticular TB with HIV status.

\begin{tabular}{|c|c|c|c|}
\hline Country & $\begin{array}{l}\text { Duration of } \\
\text { study }\end{array}$ & Number of HIV+ cases/no of OA-TB* cases $(\%)$ & Antiretroviral therapy \\
\hline India [22] & 2010-2012 & $0 / 13$ & - \\
\hline India [23] & - & $0 / 93$ & - \\
\hline Thailand [24] & 1997-2006 & $1 / 77$ & - \\
\hline Nigeria $[25]$ & 1998-2009 & $0 / 97^{* *}$ & \\
\hline $\begin{array}{l}\text { France [26] (including 74\% African } \\
\text { immigrants) }\end{array}$ & 1980-1994 & $1 / 206^{* *}$ & \\
\hline $\begin{array}{l}\text { United Kingdom [27] (including 89\% South } \\
\text { Asian immigrants) }\end{array}$ & $1988-2005$ & $0 / 44$ & - \\
\hline $\begin{array}{l}\text { Denmark [28] (including 50\% Somalian } \\
\text { refugees) }\end{array}$ & $1993-1997$ & $3 / 26^{* *}$ & - \\
\hline US [29] & $1999-2003$ & $1 / 31(3.2 \%)$ & All on ARV therapy \\
\hline China [30] & 2011-2012 & $0 / 43$ & - \\
\hline Thailand [31] & 1994-2002 & $1 / 27(3.7 \%)$ & - \\
\hline
\end{tabular}

OA-TB: osteoarticular TB; ARV therapy: antiretroviral therapy.

${ }^{*}$ Extraspinal OA-TB cases only.

** Spine and extraspinal OA-TB cases combined.

further to opportunistic infections, including TB [15]. The use of MTX in HIV positive individuals may be acceptable in the setting of a CD 4 count $>200$, particularly if ARV therapies are prescribed and if the patient is closely followed up.

We treated our patient with antituberculous therapy and an intra-articular corticosteroid injection, with a fairly dramatic resolution of signs and symptoms and restoration of joint function. The rationale for this management approach was based on the postulated role of the immune-mediated response to $\mathrm{TB}$ in the development of joint damage in OA-TB. Reducing inflammation may preserve the articular cartilage and joint space. In a study of rabbits with staphylococcal septic arthritis, intra-articular steroids reduced joint damage [16]. A similar approach in humans may be beneficial [17]. In two randomized placebo-controlled trials in children with bacterial arthritis, adjuvant intravenous corticosteroids in combination with antibiotic therapy reduced the clinical symptoms and improved outcomes without any adverse effects $[18,19]$.

Adjuvant corticosteroids reduce complications and improve survival in TB meningitis and in the case of TB pericarditis reduce the incidence of constrictive pericarditis, which may be analogous to joint destruction and contractures in the setting of OA-TB $[20,21]$. Randomized controlled studies would establish the role of adjuvant intra-articular corticosteroids in the management of OA-TB.

In summary, this case is a relatively unusual presentation of ExP-TB in an HIV positive patient. The diagnosis was aided by a positive GeneXpert test, and an excellent outcome was achieved. Adjuvant intra-articular corticosteroids may have hastened resolution of the clinical symptoms and signs of infection.

\section{Competing Interests}

The authors declare that they have no competing interests.

\section{References}

[1] World Health Organisation, Key indicators for the WHO African Region Global Tuberculosis Report 2014, World Health Organization, Geneva, Switzerland, 2014.

[2] M. M. Madkour, A. J. Kudwah, and M. A. El Bagi, Tuberculosis, Springer, Berlin, Germany, 2004.

[3] J. E. Jellis, "Human immunodeficiency virus and osteoarticular tuberculosis," Clinical Orthopaedics and Related Research, no. 398, pp. 27-31, 2002.

[4] B. Hodkinson, E. Musenge, and M. Tikly, "Osteoarticular tuberculosis in patients with systemic lupus erythematosus," Quarterly Journal of Medicine, vol. 102, no. 5, pp. 321-328, 2009.

[5] M. Steyn, Y. Scholtz, D. Botha, and S. Pretorius, “The changing face of tuberculosis: trends in tuberculosis-associated skeletal changes," Tuberculosis, vol. 93, no. 4, pp. 467-474, 2013.

[6] M. Fuentes Ferrer, L. Gutierrez Torres, O. Ayala Ramírez, M. R. Zarzuelo, and N. Del Prado González, "Tuberculosis of the spine. A systematic review of case series," International Orthopaedics, vol. 36, no. 2, pp. 221-231, 2012.

[7] R. Dunn, A. van der Horst, and S. Lippross, "Tuberculosis of the spine-prospective neurological and patient reported outcome study," Clinical Neurology and Neurosurgery, vol. 133, pp. 96-101, 2015.

[8] C. Anley, A. Brandt, and R. Dunn, "Magnetic resonance imaging findings in spinal tuberculosis: comparison of HIV positive and negative patients," Indian Journal of Orthopaedics, vol. 46, no. 2, pp. 186-190, 2012.

[9] S. Danaviah, J. A. Sacks, K. P. S. Kumar et al., "Immunohistological characterization of spinal TB granulomas from HIVnegative and -positive patients," Tuberculosis, vol. 93, no. 4, pp. 432-441, 2013.

[10] L. Maynard-Smith, N. Larke, J. A. Peters, and S. D. Lawn, "Diagnostic accuracy of the Xpert MTB/RIF assay for extrapulmonary and pulmonary tuberculosis when testing nonrespiratory samples: a systematic review," BMC Infectious Diseases, vol. 14, no. 1, article 709, 2014. 
[11] M. Held, M. Laubscher, H. J. Zar, and R. N. Dunn, "GeneXpert polymerase chain reaction for spinal tuberculosis: an accurate and rapid diagnostic test," Bone and Joint Journal, vol. 96, no. 10, pp. 1366-1369, 2014.

[12] V. Pandey, K. Chawla, K. Acharya, S. Rao, and S. Rao, "The role of polymerase chain reaction in the management of osteoarticular tuberculosis," International Orthopaedics, vol. 33, no. 3, pp. 801-805, 2009.

[13] V. K. Aggarwal, D. Nair, G. Khanna, J. Verma, V. K. Sharma, and S. Batra, "Use of amplified Mycobacterium tuberculosis direct test (Gen-probe Inc., San Diego, CA, USA) in the diagnosis of tubercular synovitis and early arthritis of knee joint," Indian Journal of Orthopaedics, vol. 46, no. 5, pp. 531-535, 2012.

[14] G. García-Elorriaga, O. Martínez-Elizondo, G. Del Rey-Pineda, and C. González-Bonilla, "Clinical, radiological and molecular diagnosis correlation in serum samples from patients with osteoarticular tuberculosis," Asian Pacific Journal of Tropical Biomedicine, vol. 4, no. 7, pp. 581-585, 2014.

[15] M. Tikly, "The scourge of HIV infection in sub-Saharan Africa-a rheumatological perspective," Journal of Rheumatology, vol. 38, no. 6, pp. 973-974, 2011.

[16] A. J. Wysenbeek, J. Volchek, M. Amit, D. Robinson, I. Boldur, and Z. Nevo, "Treatment of staphylococcal septic arthritis in rabbits by systemic antibiotics and intra-articular corticosteroids," Annals of the Rheumatic Diseases, vol. 57, no. 11, pp. 687-690, 1998.

[17] S. E. Lane and P. Merry, "Intra-articular corticosteroids in septic arthritis: beneficial or barmy?" Annals of the Rheumatic Diseases, vol. 59, article 240, 2000.

[18] L. Harel, D. Prais, E. Bar-On et al., "Dexamethasone therapy for septic arthritis in children: results of a randomized double-blind placebo-controlled study," Journal of Pediatric Orthopaedics, vol. 31, no. 2, pp. 211-215, 2011.

[19] C. M. Odio, T. Ramirez, G. Arias et al., "Double blind, randomized, placebo-controlled study of dexamethasone therapy for hematogenous septic arthritis in children," Pediatric Infectious Disease Journal, vol. 22, no. 10, pp. 883-888, 2003.

[20] B. M. Mayosi, M. Ntsekhe, J. Bosch et al., "Prednisolone and Mycobacterium indicus pranii in tuberculous pericarditis," The New England Journal of Medicine, vol. 371, no. 12, pp. 1121-1130, 2014.

[21] S. Wasserman and G. Meintjes, "The diagnosis, management and prevention of HIV-associated tuberculosis," South African Medical Journal, vol. 104, no. 12, pp. 886-893, 2014.

[22] N. Arathi, F. Ahmad, and N. Huda, "Osteoarticular tuberculosis-a three years' retrospective study," Journal of Clinical and Diagnostic Research, vol. 7, no. 10, pp. 2189-2192, 2013.

[23] V. Agashe, S. Shenai, G. Mohrir et al., "Osteoarticular tuberculosis-diagnostic solutions in a disease endemic region," Journal of Infection in Developing Countries, vol. 3, no. 7, pp. 511-516, 2009.

[24] C. Foocharoen, R. Nanagara, T. Foocharoen, P. Mootsikapun, S. Suwannaroj, and A. Mahakkanukrauh, "Clinical features of tuberculous septic arthritis in Khon Kaen, Thailand: a 10year retrospective study," Southeast Asian Journal of Tropical Medicine and Public Health, vol. 41, no. 6, pp. 1438-1446, 2010.

[25] E. Iyidobi, C. Nwadinigwe, and R. Ekwunife, "Management of musculoskeletal tuberculosis in enugu, Nigeria," Tropical Medicine \& Surgery, vol. 1, pp. 1-3, 2013.

[26] E. Pertuiset, J. Beaudreuil, A. Horusitzky et al., "Epidemiologic patterns of bone and joint tuberculosis in adults. A retrospective study of 206 cases," Presse Medicale, vol. 26, no. 7, pp. 311-315, 1997.

[27] D. S. Sandher, M. Al-Jibury, R. W. Paton, and L. P. Ormerod, "Bone and joint tuberculosis: cases in Blackburn between 1988 and 2005," The Journal of Bone \& Joint Surgery —British Volume, vol. 89, no. 10, pp. 1379-1381, 2007.

[28] S. Houshian, S. Poulsen, and P. Riegels-Nielsen, "Bone and joint tuberculosis in Denmark: increase due to immigration," Acta Orthopaedica Scandinavica, vol. 71, no. 3, pp. 312-315, 2000.

[29] J. Marquez, C. S. Restrepo, L. Candia, A. Berman, and L. R. Espinoza, "Human immunodeficiency virus-associated rheumatic disorders in the HAART era," Journal of Rheumatology, vol. 31, no. 4, pp. 741-746, 2004.

[30] S.-T. Chen, L.-P. Zhao, W.-J. Dong et al., “The clinical features and bacteriological characterizations of bone and joint tuberculosis in China," Scientific Reports, vol. 5, Article ID 11084, 2015.

[31] P. Lertsrisatit, K. Nantiruj, K. Totemchokchyakarn, and S. Janwityanujit, "Extraspinal tuberculous arthritis in HIV era," Clinical Rheumatology, vol. 26, no. 3, pp. 319-321, 2007. 


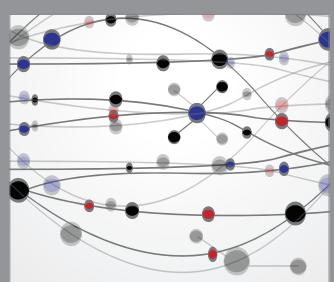

The Scientific World Journal
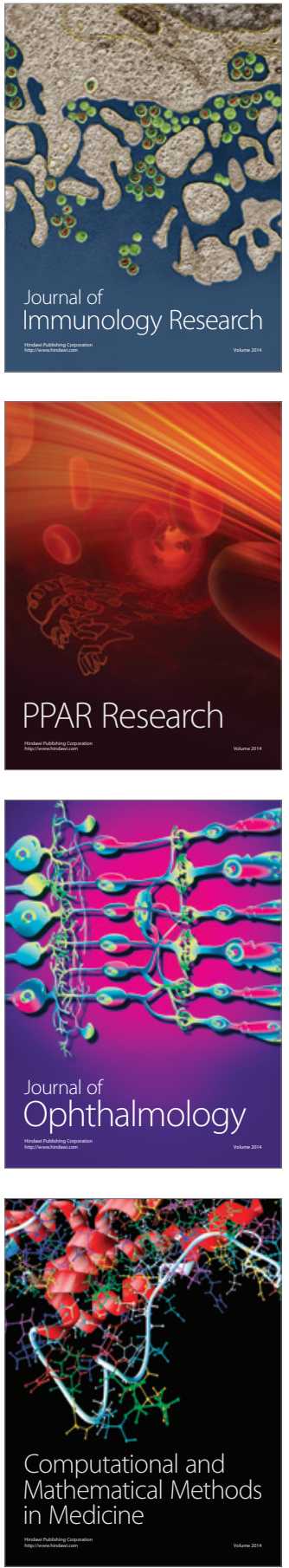

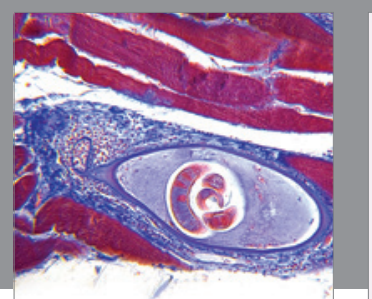

Gastroenterology Research and Practice

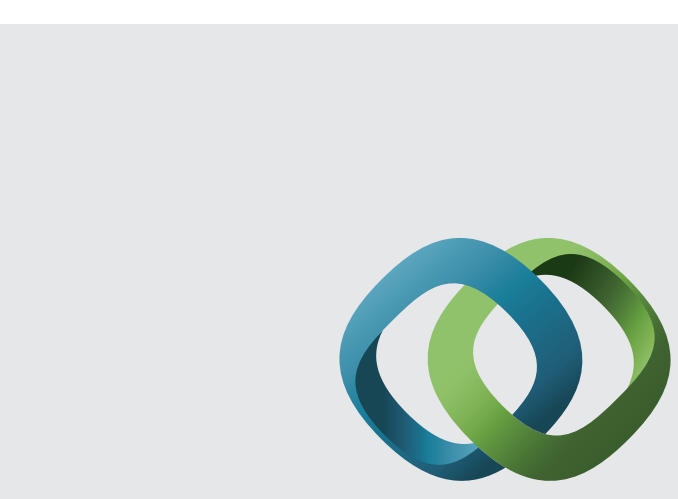

\section{Hindawi}

Submit your manuscripts at

http://www.hindawi.com
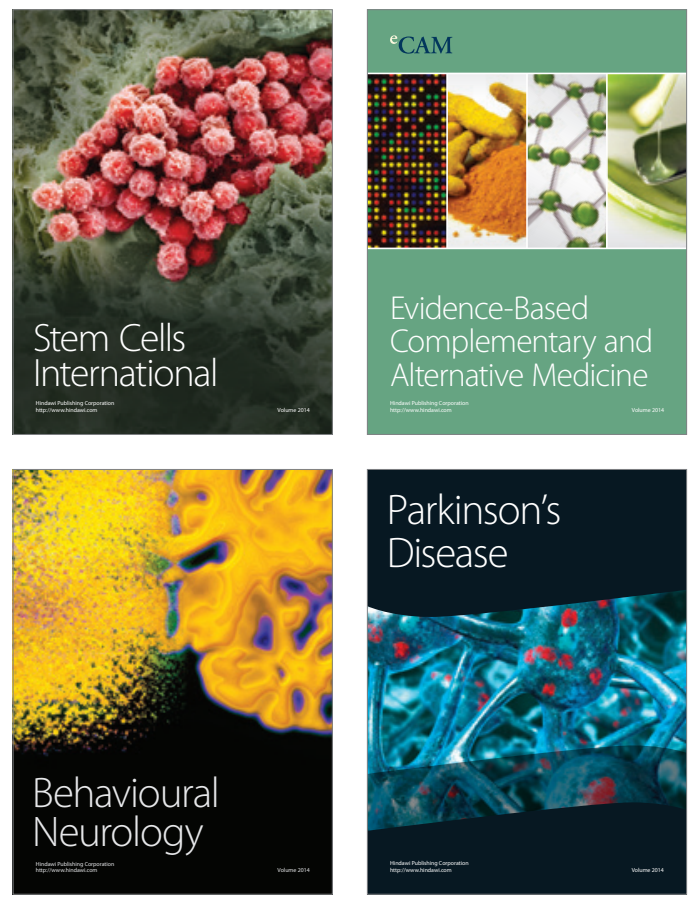
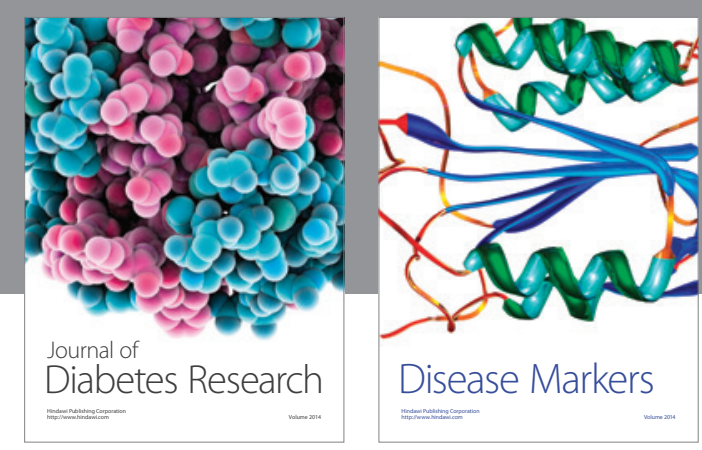

Disease Markers
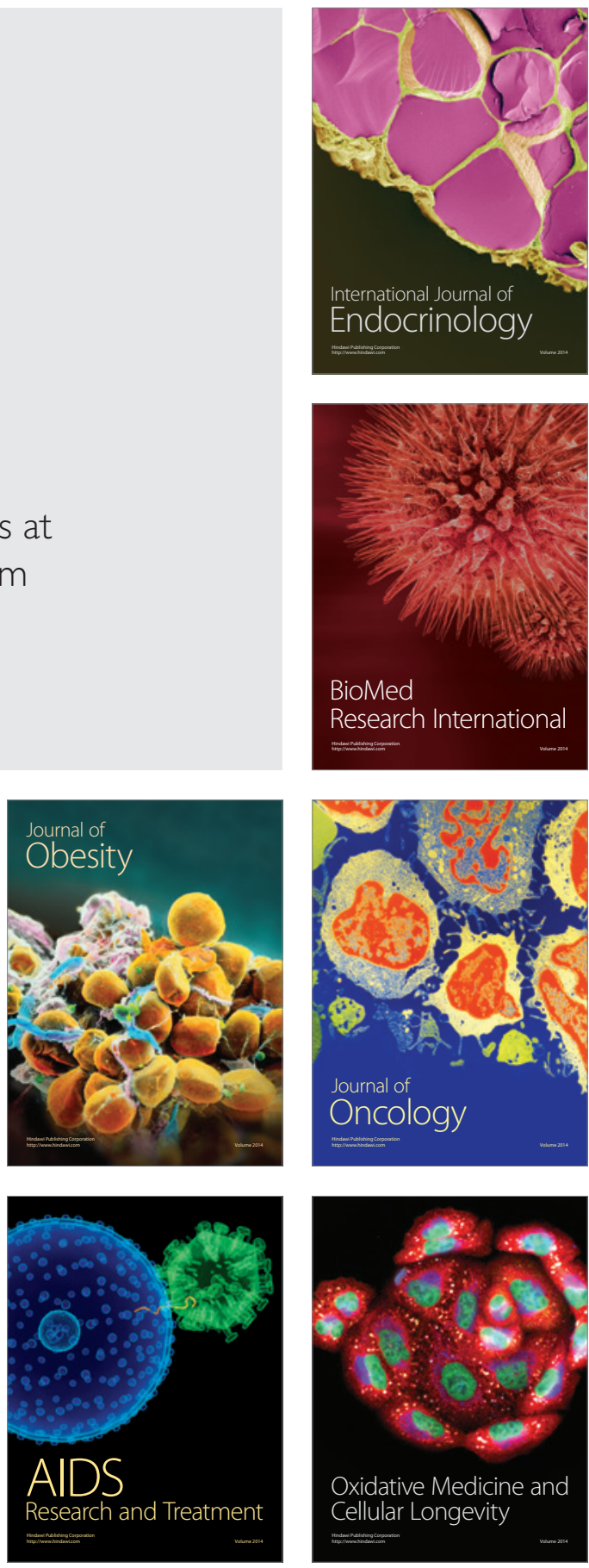